et celle-ci se situe a la place normale de la pince gauche; la mitoyenne gauche étant placée normalement, la pince gauche fait éruption à l'intérieur de l'arcade dentaire. Voir dessin $n^{\circ} 3$.

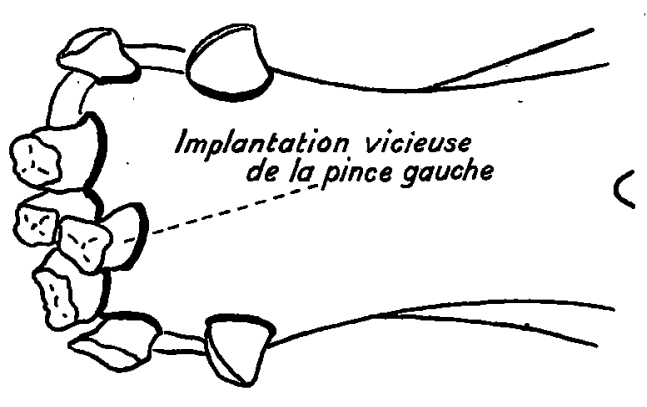

Schéma no 3

c) Anomalies de nombre. - Les variations numéraires peuvent être en plus ou en moins.

Dents surnuméraires. - Deux fois il fut observé une prémolaire caniniforme supplémentaire adjacente à la normale.

Absence de certaines dents. - Des prémolaires et des molaires peuvent manquer, La $2^{\circ}$ prémolaire inférieure manquait d'un seul côté trois fois; une fois, elle était absente de chaque arcade. L'absence des molaires n'a été observée que du côté droit. Au maxillaire supérieur, la $2^{\text {e }}$ molaire manque dans un cas; à l'inférieur, on a pu noter l'absence de la $1^{\text {re }}$ molaire deux fois, de la $2^{\text {c molaire }}$ une fois.

Nous ne considérons pas comme une anomalie l'absence d'une ou de plusieurs prémolaires caniniformes. La plus grande fantaisie présidait à leur éruption chez les animaux examinés en provenance du Sud oranais. Faut-il voir là une evolution tendan à la disparition de ces dents? C'est notre avis. Le Commandant Cauvet pourrait y voir une interpénétration de ses deux types de dromadaires : l'arabe et l'africain, ces prémolaires pouvant manquer chez les animaux du type africain. Mais l'existence de ce type africain n'est pas démontrée. Selon Cauvet, le dromadaire « africain » aurait deux prémolaires sériées au maxillaire inférieur, mais n'est-ce pas là la mauvaise interprétation d'une donnée morphologique. En effet, nous avons remarqué souvent que par suite d'un articulé molaire défectueux, la $1^{\text {re }}$ molaire se divisait par l'usure en deux simulant ainsi une dent supplementaire; mais, par la coupe, on voit qu'il ne s'agit là que d'une même dent. Voir dessin no 4.

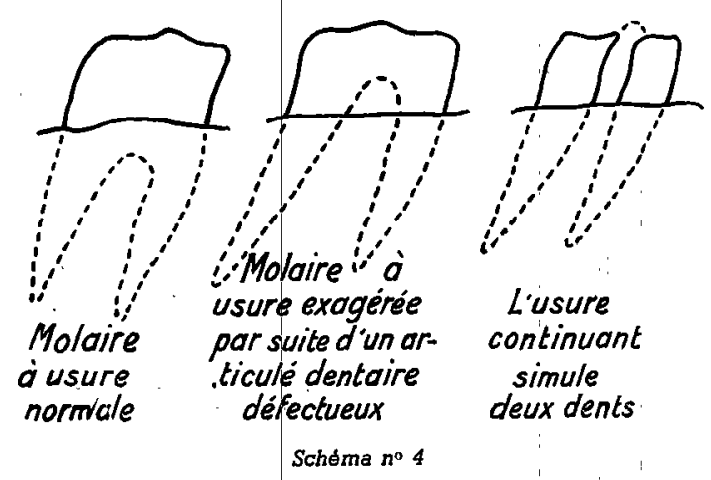

\title{
Observations sur l'emploi du vaccin de culture anti-péripneumonique en milieu sain et contaminé
}

\author{
par R. LARRAT
}

LAA péripneumonie fut introduite dans le troupeau du centre sérumigène de Makhana par un lot d'animaux réceptionnés dans la première quinzaine de Septembre 1943.

A partir de ce moment la maladie évolue jusqu'en Octobre 1944 lentement, irrégulièrement, avec deux poussées brutales (Janvier-Février et JuilletAoût) et une période silencieuse (Mai).

Ia totalité du troupeau contaminé fut isolée et nous avons pu suivre le comportement des animaux vaccinés avant et après la période de contamination.

La dose de culture-vaccin utilisée fut pour tous les animaux de 2 centimetres cubes.
Voir page suivante, dans le tableau, les observations qui ont été faites :

Commentaire. - La date de contamination possible est le ler Septembre 1943. Ce qui réduit singulièrement le délai de protection conférée par le virus-vaccin; il ne dépasse guère 250 jours et, tout au moins dans un cas, est inférieur à 198 jours.

On peut toutefois considérer que le producteur $79 \mathrm{~B}$, exposé à la contagion 32 jours après la vaccination, était encore en état de réceptivité (compte tenu des délais nécessaires pour la création de l'immunité).

Il n'en va pas de meme du $107 \mathrm{D}$. Le délai de 67 jours entre la vaccination et la mort doit etre évidemment réduit de la durée des periodes d'incubation et d'évolution.

La contamination étant possible à compter du ler Septembre 1943, dans le cas le plus extrême la protection conférée par le vaccin n'a pas dépassé 103 jours. 
VACCINATION PAR VIRUS-VACCIN EN MILIEU SAIN

\begin{tabular}{|c|c|c|c|c|c|c|}
\hline $\begin{array}{l}\text { NUMÉRO } \\
\text {-des } \\
\text { producteurs }\end{array}$ & $\begin{array}{c}\text { DATE } \\
\text { de la } \\
\text { vaccination }\end{array}$ & 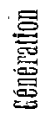 & $\begin{array}{c}\text { DATE' } \\
\text { de lá mort }\end{array}$ & $\begin{array}{l}\text { DÉLAI ÉCOULÉ } \\
\text { (jours) }\end{array}$ & $\begin{array}{l}\text { DELAI ECOULE } \\
\text { par rapport à la } \\
\text { période probable } \\
\text { du contage. }\end{array}$ & LÉSIONS PULMONAIREJ \\
\hline $79 \mathrm{~B}$ & $30-7-43$ & 23 & $13-2-44$ & 198 & 32 & Hépatisation bilatérale. \\
\hline $107 \mathrm{D}$ & $20-5-43$ & 23 & $1-2-44$ & 357 & 103 & $\therefore \quad \gg \quad \because \quad \gg$ \\
\hline I $\mathrm{B}$ & $25-12-43$ & 22 & $4-1-44$ & 375 & 249 & Hépatisation poumon gauche. \\
\hline $2 \mathrm{D}$ & 》 & ") & $14-1-44$ & 385 & 249 & Hépatisation bilatérale. \\
\hline $98 \AA$ & 》 & 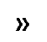 & $6-2-44$ & 408 & 249 & is \\
\hline $98 \mathrm{~A}$ & $n$ & " & $12-2-44$ & 414 & ") & $\therefore$ \\
\hline $71 \AA$ & » & $»$ & $13-2-44$ & 415 & ) & Hépatisation plus accusèe à gauche. \\
\hline $16 \mathrm{~B}$ & 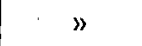 & $\gg$ & $18-2-44$ & 420 & \#) & Atteinte bilatérale. \\
\hline $18 \mathrm{C}$ & $"$ & $\gg$ & $3-3-44$ & 433 & '» & Hépatisation bilatérale. \\
\hline $35 \mathrm{D}$ & 》 & 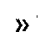 & $12-2-44$ & 473 & $»$ & Poumon droit entièrement hépatisé. \\
\hline
\end{tabular}

VACCINATION ET REVACCINATION PAR VIRUS-VACCIN EN MILIEU SAIN

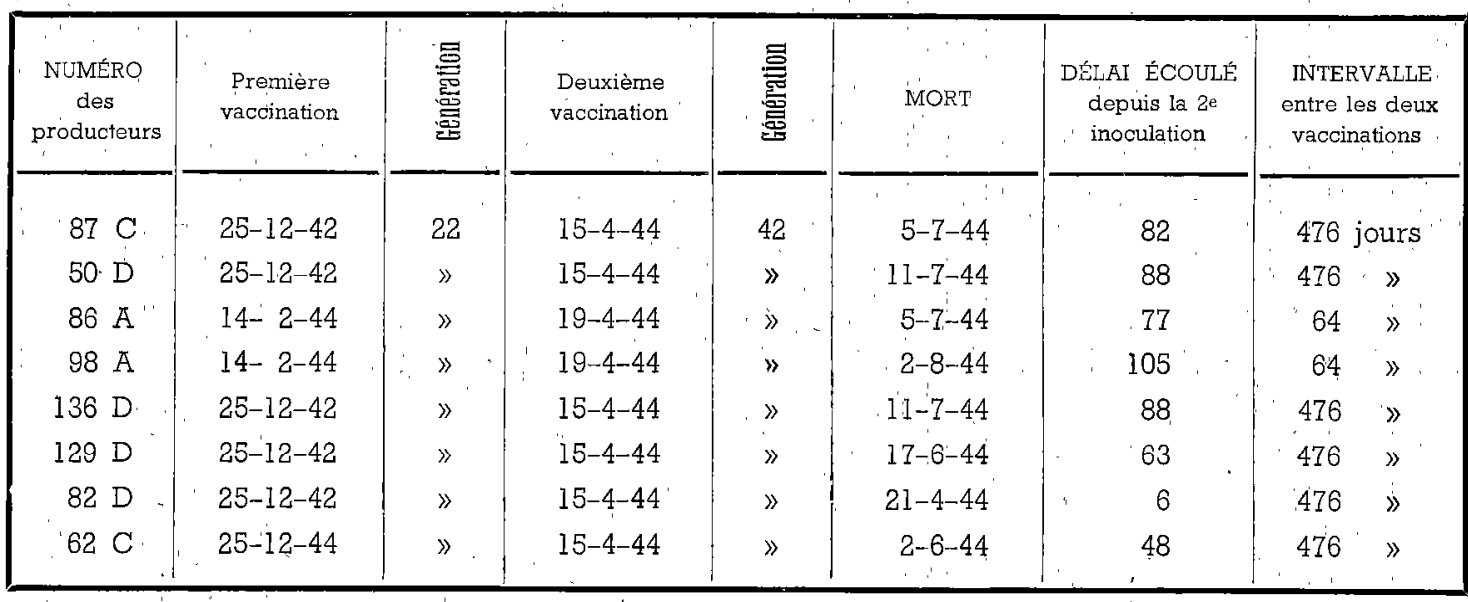

Commentaire. - Cas de revaccination. L'animal revacciné se comporte coimme un animal à la primo-vaccination

quand l'intervalle entre les deix vaccinations successives est de 64 jours.

\section{VACCINATION PAR VIRUS-VACCIN ET REVACCINATIONS SUCCESSIVES PAR VACCIN FORMOLÉ EN MILIEU CONTAMINÉ}

\begin{tabular}{|c|c|c|c|c|c|c|}
\hline $\begin{array}{c}\text { NUMÉRO } \\
\text { des } \\
\text { producteurs }\end{array}$ & $\begin{array}{c}\text { PREMIÈRE } \\
\text { vaccination } \\
\text { virus-vacin }\end{array}$ & 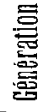 & $\begin{array}{c}\text { DEUXIEME } \\
\text { vaccination } \\
\text { vaccin formolé }\end{array}$ & $\begin{array}{c}\text { TROISIÈME } \\
\text { vaccination } \\
\text { vaccin formolé }\end{array}$ & MORT & $\begin{array}{l}\text { DÉLAI ÉCOULÉ } \\
\text { depuis la première } \\
\text { vaccination (jours) }\end{array}$ \\
\hline $19 \mathrm{~B}$ & 9611 & 30 & $22-7-44$ & $27-8-44$ & $14-10-44$ & 127 \\
\hline $116 \mathrm{D}$ & $7-5-44$ & 42 & - & - & $6-10-44$ & 152 \\
\hline $114 \mathrm{D}$ & $7-5-44$ & 42 & - & - & $5-9-44$ & 121 \\
\hline $21 \mathrm{~B}$ & $9-5-44$ & 30 & - & - & $6-9-44$ & 89 \\
\hline $112 \bar{A}$ & $19-4-44$ & 42 & - & - & $30-10-44$ & 194 \\
\hline
\end{tabular}

Commentaire. - En milieu contaminé, la vaccination par virus-vaccin (dose : $2 \mathrm{cc}$ ) et deux revaccinations successives rapprochées (vaccin' formolé Curasion) ne modifient' pas le pró- cessus de contamination. Les sujets vaccinés et revaccinés succombent de 3 à 6 mois après l'injection du virus-vaccin (lésions de péripneumonie chronique) 
VACCINATION PAR VIRUS-VACCIN EN MILIEU CONTAMINÉ

\begin{tabular}{|c|c|c|c|c|c|c|}
\hline $\begin{array}{c}\text { NUMÉRO } \\
\text { des } \\
\text { producteurs }\end{array}$ & $\begin{array}{c}\mathrm{D} \Lambda \mathrm{TE} \\
\text { inoculation } \\
\text { virus-vaccin } \\
\text { accéléré }\end{array}$ & 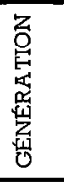 & $\begin{array}{c}\text { DATE } \\
\text { de la.mort }\end{array}$ & 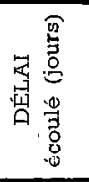 & LÉSIO & ONS PULMONATRES \\
\hline $43 \AA$ & $19-4-44$ & 42 & $25-4-44$ & 6 & Atteinte bilatérale & \\
\hline $68 \mathrm{~A}$ & $19-4-44$ & 42 & $26-4-44$ & 7 & $-\quad \quad-$ & \\
\hline $57 \mathrm{~B}$ & $29-9-43$ & 23 & $30-10-43$ & 31 & Hépatisation bilaté & térale. \\
\hline $59 \mathrm{~B}$ & $29-9-43$ & 23 & $30-10-43$ & 31 & - & - \\
\hline $100 \AA$ & $20-9-43$ & 23 & $30-12-43$ & 40 & Hépatisation plus & accusée à gauche \\
\hline $132 \mathrm{~B}$ & $12-12-43$ & 29 & $21-1-44$ & 40 & Hépatisation bilate & térale. \\
\hline $60^{\prime} \mathrm{B}$ & $12-12-43$ & 29 & $22-1-44$ & 41 & - & - \\
\hline $83 \mathrm{C}$ & $15-11-43$ & 29 & $26-12-43$ & 41 & Atteinte bilatérale & hépatique incomplète. \\
\hline $17 \mathrm{C}$ & $28-5-44$ & 42 & $10-7-44$ & 43 & Hépatisation bilaté & térale plus accusée à gauche. \\
\hline $7 \AA$ & $15-11-43$ & 29 & $30-12-43$ & 45 & Atteinte bilatérale & hepatique incomplète. \\
\hline $17 \AA$ & $29-9-43$ & 23 & $13-11-43$ & 45 & Hépatisation pourr & mon gauche. \\
\hline $34 \mathrm{~B}$ & $29-9-43$ & 23 & $14-11-43$ & 46 & Hépatisation bilat & térale œedème abdómen. \\
\hline $106 \mathrm{D}$ & $15-11-43$ & 29 & $31-12-43$ & 46 & Hépatisation bilaté & érale plus accusée à gauche. \\
\hline $104 \mathrm{D}$ & $15-11-43$ & 29 & $3-1-44$ & 49 & Hépatisation bilat & térale. \\
\hline $56 \AA$ & $15-11-43$ & 29 & $4-1-44$ & 50 & - & - \\
\hline $133 \mathrm{~B}$ & $12-12-43$ & 29 & $1-2-44$ & 50 & Pleuro-pneumonie & \\
\hline $14 \mathrm{C}$ & $28-5-44$ & 42 & $31-7-44$ & 54 & Hépatisation bilat & térale. \\
\hline $78 \mathrm{~B}$ & $12-12-43$ & 29 & $9-2-44$ & 60 & Atteinte poumon & gauche. \\
\hline $12 \mathrm{D}$ & $15-11-43$ & 29 & $14-1-44$ & 60 & Atreinte bilaterale & . \\
\hline $54 \mathrm{~B}$ & $12-12-43$ & 29 & $11-2-44$ & 62 & Hépatisation bilat & térale. \\
\hline $35 \mathrm{~A}$ & $7-5-44$ & 42 & $15-7-44$ & 69 & Hépatisation plus & accusée à gauche. \\
\hline $15 \mathrm{~A}$ & $15-11-43$ & 29 & 23- I-44 & 69 & Atteinte bilatérale & . \\
\hline $38 \mathrm{~A}$ & $22-9-43$ & 23 & $10-12-43$ & 72 & Hépatisation pour & mon gauche. \\
\hline $31 \mathrm{D}$ & $11-10-43$ & 25 & $31-12-43$ & 81 & Hépatisation bilaté & térale. \\
\hline $6 \AA$ & $15-11-43$ & 29 & $6-2-44$ & 83 & Poumon droit gan & ngrène épanchement pleural. \\
\hline $14 \mathrm{~A}$ & $15-11-43$ & 29 & $7-2-44$ & 84 & Hépatisation bilat & térale. \\
\hline $28 \mathrm{~A}$ & $19-4-44$ & 42 & $15-7-44$ & 87 & Poumon gauche e & entièrement hépatisé. \\
\hline $19 \AA$ & $15-11-43$ & 29 & $13-2-44$ & 90 & Atteinte unilatéral & le gauche. \\
\hline I6 A & $19-4-44$ & 42 & $26-7-44$ & 98 & Lésions bilatérale & s. \\
\hline $135 \AA$ & $19-4-44$ & 42 & $28-7-44$ & 100 & Atteinte bilatérale & e. \\
\hline $137 \mathrm{D}$ & $11-10-43$ & 25 & $4-2-44$ & 116 & Hépatisation bilaté & térale. \\
\hline $7 \mathrm{C}$ & $29-9-43$ & 23 & $7-2-44$ & 131 & Lésions bilatérale & es. \\
\hline
\end{tabular}

Commentaire. - En milieu contaminé le virus-vaccin n'empêche nullement l'évolution de la péripneumonie, 2 fors sur 32 ( $43 \mathrm{~A}$ et $68 \mathrm{~A}$ ), il semble mème l'accélérer (réaction allergique). Dans l'observation, la mortalité s'échelonne régulièrement du 6e jour au $1 / 31 \%$, après la vaccination, sans rémission ni fissure. 
VACCINATION PAR VIRUS-VACCIN ET REVACCINATION PAR VACCIN-FORMOLÉ EN MILIEU CONTAMINÉ

\begin{tabular}{|c|c|c|c|c|c|c|c|c|c|c|}
\hline $\begin{array}{l}\text { NUMÉRO } \\
\text { des } \\
\text { producteurs }\end{array}$ & $\begin{array}{c}\text { Première } \\
\text { vaccination } \\
\text { (virus-vaccin) }\end{array}$ & 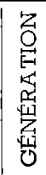 & $\begin{array}{c}\text { Deuxième } \\
\text { vaccination } \\
\text { (vaccin-formolé) }\end{array}$ & MORT & \multicolumn{2}{|c|}{$\begin{array}{l}\text { DÉLAI ÉCOULÉ } \\
\text { à partir de la l re } \\
\text { vaccination }\end{array}$} & \multicolumn{2}{|c|}{$\begin{array}{l}\text { DÉLAI ÉCOULÉ } \\
\text { à partir de la } 2 e \\
\text { vaccination }\end{array}$} & \multicolumn{2}{|c|}{$\begin{array}{c}\text { INTERVALLE } \\
\text { eńtre'Ies deux } \\
\text { vaccinations }\end{array}$} \\
\hline $13 \mathrm{C}$ & $18-5-44$ & 42 & $20-7-44$ & $20-8-44$ & 93 & ours & 30 & ours & 63 & ours \\
\hline $26 \mathrm{~B}$ & $9-6-44$ & 30 & $22-7-44$ & $10-8-44$ & 62 & 》) & 19 & $»$ & 43 & $\gg$ \\
\hline $43 . \mathrm{D}$ & $7-5-44$ & 42 & $22-7-44$ & $9-8-44$ & 94 & $\gg$ & 18 & $\gg$ & 76 & $»$ \\
\hline $84 A$ & $11-4-44$ & 42 & $22-7-44$ & $26-8-44$ & 137 & 》 & 35 & $»$ & 102 & $\gg$ \\
\hline $1 ? .1$ & $7-5-44$ & 42 & $22-7-44$ & $24-7-44$ & 78 & $\gg$ & 3 & $»$ & 76 & $》$ \\
\hline $13 \mathrm{C}$ & $18-5-44$ & 42 & $20-7-44$ & $20-8-44$ & 94 & $\gg$ & 31 & $\gg$ & 63 & $\gg$ \\
\hline $3 \mathrm{C}$ & $28-5-44$ & 42 & $27-7-44$ & $16-8-44$ & 80 & $\gg$ & 20 & $》$ & 60 & $》$ \\
\hline $5 \mathrm{C}$ & $28-5-44$ & 42 & $22-7-44$ & $21-8-44$ & 85 & $》$ & 30 & $\gg$ & 55 & $\gg$ \\
\hline $37 \mathrm{~B}$ & $9-6-44$ & 30 & $22-7-44$ & $17-8-44$ & 69 & $\gg$ & 26 & $》$ & 43 & $》$ \\
\hline$\approx-7 \dot{C}$ & $28+b-44$ & 42 & $22-1-44$ & $1-8-44$ & 70 & $\gg$ & 10 & $\gg$ & 60 & $\gg$ \\
\hline $35 \mathrm{D}$ & $7-5-44$ & 42 & $22-7-44$ & $31-7-44$ & 85 & 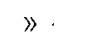 & 9 & $»$ & 76 & $\gg$ \\
\hline $13 \mathrm{~A}$ & $19-4-44$ & 42 & $22-7-44$ & $19-8-44$ & 123 & $\gg$ & 28 & & -94 & $»$ \\
\hline
\end{tabular}

Commentaire. - Inefficacité de la vaccination par virusvaccin (dose : 2 cc.) et de la revaccination par vaccin formolé effectuée 2 à 3 mois après l'inoculation du virus-vaccin. La marche de la péripneumonie dans un troupeau exposé à la contamination ne s'en trouve pas modifié. 